cine succeed, there will be still only too ample scope for the physician and surgeon. It is for us to maintain, in our day, the dignity and usefulness of a profession which has included in it so many good and illustrious men, and which has for so many centuries been one of the foremost branches of intellectual activity. The foundations of medical science have been laid in an antiquity beyond the reach of historical investigation; its terms are the monuments of forgotten theories; in its progress, it has reflected the myriad aspects of human thought; to its storehouses of knowledge, all civilised nations have borne their contributions. If, in its course of development, it has shared the errors and shortcomings which are inseparable from human progress, none the less have its advances been fairly abreast of those made in other branches of knowledge. I have no fear but that this will continue to be so, and that as medicine is, and must be, one of the most beneficial, it will also remain one of the most liberal and enlightened of professions.

\section{ADDRESS IN MEDICINE.}

\author{
WILLIAM M. ORD, M.D., F.R.C.P.,
} Physician to St. Thomas's Hospital.

\section{ON SOME DISORDERS OF NUTRITION RELATED WITH AFFECTIONS OF THE NERVOUS SYSTEM.}

SUBJECTs of discourse are assuredly not lacking when an address in medicine is to be delivered. To me, thinking of many-for example, of subjects historical, of subjects ethical, of subjects polemical-has come the final selection of a subject which, appertaining as yet very little to any one of these categories, has for some years very largely occupied my thoughts. A few minutes after I received the honour of being invited by your President to deliver this address, I happened to meet a friend whose advice I value very much. He at once suggested that I should talk about some subjest to which my thoughts had been much directed, and specified certain disorders of nutrition related with affections of the nervous system, which had certainly interested me very deeply, and were capable of general discussion. I took the advice, and set to work to write the paper. Presently I found that one subject with which I proposed to deal, the subject of chronic arthritis, was to be handled in the Section of Medicine by my able friend and colleague in the last International Medical Congress, Dr. Dyce Duckworth, and that the influence of the nervous system on normal and abnormal nutrition was to be introduced in the Section of Physiology and Pathology by Dr. Alexander. On reflection, I decided not to alter my intention. The fact that the subject which I had chosen was also in the thoughts of others, promised me a critical audience ; and in the multiplying of observations, probably all regard. ing the questions from different standpoints, there was offered, so far, greater probability of apprehending the truth.

Let me invite you then to follow me in considering some perversions of nutrition of the body, or its parts, brought about, or appearing to be brought about, by the morbid agency of the nervous system.

I will ask you to let me put a sort of label on the matters of discourse, and to speak of them as Neurotic Dystrophies. They will include conditions of overnutrition, and of undernutrition, where the variation is of quantity rather than of kind; conditions of misdirected or eccentric nutrition, where the variation is of kind as well as of quantity.

The little used, or scarcely recognised term, dystrophy, will for my purpose cover these various perversions, and the adjective neurotic will indicate the aspect from which I wish for the moment to regard them. They will not be exhaustively dealt with. This is inconsistent with the limits of an address. I shall only discuss some three or four instances, and in discussing those shall rather review than attempt to prove. The general direction of my thoughts in relation to this subject may be best illustrated by certain neurotic dystrophies of joints and muscles.

Muscular Atrophy, produced by Jolnt-lesions.-M. Charcot, in last year's Progrès Médical, has treated, with that marvellous lucidity which belongs to him, of certain effects upon the nutrition and contracture of muscles, determined to all appearance by affections of joints. That the nutrition of the muscles of limbs in which the joints are affected by chronic and painful disease is often subject to impairment, has, as M. Charcot in his paper indicates, been long ago observed. But M. Charcot's method of treatment of the correlation gives to it a new etiological aspect. Let me quote two of his cases.

A man, aged 23 , in the telegraph-service, having been previously healthy in all respects, had, about a year previous to examination, struck his right knee in jumping over a fallen tree. It is important to notice that the injury at the time did not appear to be severe, and that he walked afterwards several miles without difficulty. At length he stopped for a time, and then found himself unable to walk without a stick. For a week afterwards he kept his bed; the joint was swollen, but not very painful, but there was a remarkable loss of motor power in the limb.

At the time of M. Charcot's lecture on the case, the patient presented a weakness of the extensors of the legs, almost amounting to paralysis, associated with some loss of power and wasting of the rest of the muscles of the limb. While the whole limb was smaller in volume than the opposite limb, it was obvious that the anterior aspect of the thigh was most affected; the muscles of that region were limp, and presented no projection even at the moment of exertion.

Two things were then evident; paresis of the muscles of the limb, generally most marked in the triceps; a wasting of the muscles of the limb generally, again most marked in the triceps. Tested by electricity, the muscles and their nerves gave so little reaction, both to galvanic and faradic currents, that, to use M. Charcot's expression, one would have thought that the muscles were absent. There was a simple quantitative modification of both reactions, giving rise to the conclusion that the condition was one of simple atrophy, and not of a degenerative atrophy, with which the well known "reaction of degeneration" would have been associated. To these tests M. Charcot added a third, namely, the application of the electric spark. He placed the patient on an insulated table, and connected him with a frictional electricity machine. A spark being drawn from the front of the thigh, or from the region of the vastus internus, an energetic contraction of muscles followed. Percussion of the right triceps produced an evident contraction, and percussion of the patellar tendon determined marked shocks, not only on the side of the percussion, but also in the two upper limbs, particularly in the left. There was no ankle-clonus. The muscles of the front of the right leg and calf contracted less forcibly under electrical stimulation than the muscles of the opposite side. M. Charcot states that, at the time of his demonstration, much of the loss of power had already disappeared under the steady use of electrical stimulation. Discussing the bearings of the case with the most delicate refinement of analysis, M. Charcot grasps at once the fact that the wasting and loss of power exhibited by the muscles was out of all proportion to the severity of the injury and the amount of suffering. $\mathrm{He}$ dismisses theories of propagation of articular inflammation to the neighbouring muscles. He dismisses the theory of atrophy from prolonged inertia; and finds himself reduced to admit the existence of what he calls a deuteropathic spinal affection, giving rise to the paralysis and the atrophy. In the absence of the "reaction of degeneration," he finds himself unable to recognise any indication of a serious change in the anterior horns of the grey matter of the spinal cord, and is reduced to the suggestion of a kind of stupor or inertia of the nerve-cells. He is also reduced to the explanation of the exalted tendon-reflexes by the hypothesis that, while the cells of the affected region are in a state of torpor, there is a condition of exaggerated reflex excitability in the rest of the spinal cord.

The second case is that of a hairdresser aged 51. Here a chronic rheumatoid arthritis had affected the wrists, the shoulders, the ankles, the knees, the hips, the elbows, the fingers to a slight degree, and the cervical articulations in succession. There was neither pronounced inflammation nor pain ; but there followed a rapid wasting and a great loss of muscular power. The wasting of muscles was unequal, falling chiefly in the extensors of the limbs. These showed the same loss of sensibility to electrical stimulation which had been observed in the other case, with one exception : the right vastus externus presented the reaction of degeneration. Many of the atrophied muscles were the seat of fibrillar contractions. Some of them, the left deltoid in particular, were excitable by simple percussion. The loss of power was in excess of the wasting. The tenclon-reflexes were again strongly accentuated. To the conditions here enumerated M. Charcot adds, from observation of other cases, "contracture," tonic contraction of certain muscles, chiefly of flexors.

Summing up these and other cases, M. Charcot argues that the paresis, wastings of certain muscles, contractures of certain muscles, and the other associated symptoms, indicate an influence propagated from the affected joint or joints, incident on the spinal cord, and thence reflected to the muscles, giving rise in the one set of cases 
to contracture, where exaltation of function must be supposed, in another set of cases to atrophy, where depression of function must be supposed.

If we accept M. Charcot's conclusions, we have in this group of cases a dystrophy of muscles, brought about by irritation commencing in joints mone or less related with those muscles, propagated through centripetal nerves to the spinal cord, and reflected thence by centrifugal nerves to the muscles.

M. P. Berger has related for us some cases presenting the converse of the observations of M. Charcot just related. In M. Berger's cases, fracture of the upper part of the femur near the hip-joint was followed by arthritis of the knee; not attributable in any way to extension of inflammation through the intermediate tissues. M. Berger's observations would lead to the establishment of the possibility of a reflex influence reversing the path of the influence just quoted. In other words, we have before us observations suggesting that joints being inflamed may, by a reflex influence, give rise to dystrophies of associated mascles; and that bones and surrounding textures being injured may give rise to dystrophies of neighbouring joints. Such considerations carry us on to search for the middle term; to examine if there be any evidence indicating a direct morbid influence of the spinal cord on the nutrition of the component parts of limbs in common ; and secondly, they may lead us to inquire whether the nutrition of joints and other parts of limbs may be affected by influences propagated from viscera ; that is to say, from parts which are not components of limbs.

Ohronic Rheumatic or Rheumatoid Arthritis as work of NERVE-INFLUENCE. - Having this in view, I will ask you to accompany me in considering chronic rheumatic arthritis as the possible work of nerve-influence. I use this term, chronic rheumatic arthritis, because I am speaking in Ireland in the presence of many men who must be well acquainted with the work of Adams of Dublin. Chronic rheumatic arthritis is, as you will also know, but one of many names given to an affection of joints, spoken of by the non-medical public as rheumatic gout. The morbid lesions of this disease are of a kind justifying completely' the application to them of the term dystrophy ; for, while they include destruetive inflammation of articular cartilages, and subsequently of the bone beneath, they include also bypertrophic changes in the synovial membrane, and in the periosteum around the articular surfaces.

Here, once more, I must refer to the work of M. Charcot, whose name is associated with the remarkable observation that a form of chronic joint-disease, presenting both the atrophic and the hypertrophic lesions of chronic rheumatic arthritis, forms a part of the phenomena of tabes dorsalis. It is true that the atrophy predominates enormously; but the hypertrophy can always be recognised by any one who may care to study with care the specimens of joint-trouble exhibited by M. Charcot. The essential lesion of tabes dorsalis, as at present recognised, lies in the spinal cord, and is, so far, a central nervous lesion. But the actual seat, you will remember, is not in the grey matter, but in columns, of fibres, which, to all appearance, are the channels of a centripetal influence, flowing, at least in part, from the voluntary muscles. In fact, it is quite possible to argue that the jointlesion may be here the result of reflection of irritation, propagated to the grey matter of the spinal cord by the diseased muscle-representing fibres of the posterior root-zone; that, in other words, muscles, subjectively presented to the grey matter as in a state of irritation, can induce by reflection a dystrophy of joints. If there be any possible acceptance of the idea that joints, being irritated, can, by reflex trophic influence, affect the nutrition of muscles; and that muscles, or their centripetal norves, being irritated, can produce, also by reflex trophic influences, dystrophies of joints, we can hardly stop short of accepting a further sugrestion, to the effect that some part of the central nervous system, presumably some part in the spinal cord, presides, in a common sense, over the nutrition of organs so closely associated as joints and muscles, perhaps also over that of bones.

Turning our attention to what is known of the direct influence of the central nerrous system npon the nutrition of muscles, we know already that there is a very fair certainty of the existence of a definite relation between certain affections of the anterior horns of the grey matter of the spinal cord and atrophic affections of muscles.

Associated with an acute inflammation of groups of cells in the anterior horns, are found the phenomena of infantile and essential paralysis; associated with an inflammation of the same anterior horns, differing from that just mentioned in being chronic, and differing proluably in its method, are found the phenomena of progressive muscular atrophy. Infantile paralysis and progressive muscular atrophy have each so distinct a grouping of symptoms as to confer on each a markod clinical identity, and on each an assured independence of the other. Nevertheless, they have in common one important factor, wasting of muscles ; but the wasting of muscles is, if we may judge by their electrical reactions, not brought about by the same process in the two cases. In infantile paralysis, the reaction of degeneration leads us to infer that the nutrition of muscular (centrifugal) nerves is seriously involved. In progressive muscular atrophy, this reaction does not appear, there being only a diminution of electrical' reaction proportionate to the loss of muscular fibre.

Joint-Lesion in Progressive Muscular Atrophy.-My friend, Dr. Gulliver, of St. Thomas's Hospital, an inheritor of the observing faculty and accuracy of his celebrated father, has recently communicated to me, quite independently of this address, the notes of a case in which a joint-lesion appeared as a part of the phenomena of progressive muscular atrophy.

In studying this disease, I had long thought that there were indications, in many cases, of affections of joints as well as of muscles. Dr. Gulliver and I have often conversed on the subject, and when the patient, whose case I will now relate, came under his notice, he lost no time in bringing her to mine.

K. M., a married woman, aged 50, came under treatment in June, 1884. Of the family history nothing was ascertained. Her previous history presented nothing important, save that she had never had rheumatism.

For six or seven months she had noticed a loss of power in the left arm, but had been able to carry on her occupation of laundress till within the last six weeks. About five months ago she began to experience difficulty in speaking, which increased till, at the time of observation, she was unable to articulate in any intelligible way. She had also a growing difficulty in swallowing, with impairment of the use of the lins in movements other than those of articulation, toi instance, in blowing out a candle, and she had dribbling of saliva. Three months ago-at least, three months after the commencement of muscular feebleness-she began to experience pain in the left shoulder-joint, greatly increased by raising the arm, actively or passively. At the time of observation, the left arm was found to be much wasted, particularly in the forearm, and in the thenar and $\mathrm{hy}$ pothenar eminences. The hand had the claw-shape characteristic of progressive muscular atrophy ; it was the main en griffe of Duchenne and she could not oppose the tips of the fingers to the tip of the thumb. She could not raise the left arm to the horizontal position and all attempts to do so gave rise to much pain in the shoulcerjoint. All movement involving the shoulder-joint, whether performed voluntarily or effected by other persons, gave much pain. The joint showed no coarse changes; there was no affection of tho right arm or of the legs; the muscles of both arms answered equally to the galvanic current; those of the left appeared to react a little readily under the faradic; the knee-jerk was more active than usual in boti legs. The tendon-reflexes of the arms were investigated, but tho results were not definite. She could not speak, being able to produce nothing more than a monotonous inarticulate sound; she could not protrude the tongue, or blow out the lips. The palate was motionless: and she swallowed with difficulty.

Although the order of affection of the muscles of the arm is no recorded, the case is clearly one of progressive muscular atrophy, in which the bulbar affection is predominant. And while, as regard. the limbs, the left upper extremity was alone affected, the painful state of the left humeral articulation indicates the existence of a definite change in the nutrition of a joint belonging to the same area of innervation as that of the affected muscles; and, so far as it goes, the case tends to show that one central nervous affection may give rise to concomitant dystrophy of joint and muscle.

Muscular Wasting: Co-existext with Jornt-Disease.-For some years $I$ have been led to observe, in a certain group of cases of chronic rheumatic arthritis, the co-existence with the jointlesion, always well marked, of affeetions of muscles. These have beer not merely weakness of cxtensors, and tonic contraction of flexors, the two factors which largely determine the character of the deformities of the disease, but marked and excessive wasting of muscles, closely resembling those of progressive muscular atrophy. Together with these, I have noted the existence of fibrillar tremors. and of electrical reactions like those of progressive muscular atrophy in the general, but with some indications of less loss of galvanic thai of faradic sensibility, with some slight indication of the reaction of degeneration.

In addition to those, I have noticed, as others before me have noticed, a wasting of the tissues other than the muscles of limbs.

These concern, in the hands, loss of substance in the soft parts of the digits, the wasting of the skin, which brings about a satiny 0 
glossy quality of the surface, and a dwindling of the nails, which we see carried to the full in extreme true gouty affection of the fingers, where the nails become small scaly appendages of the carrot-like digits. In some cases I have also observed exaggeration of the so-called tendon-reflexes, and in some, fibrillar tremors. In fact, as they present themselves to me, these are cases of progressive dystrophy of joints marching with progressive atrophy of muscles, and with atrophy: of the other tissues of limbs. My friend, Dr. Hadden, who has taken great interest in these cases, has recently presented a paper to the Clinical Society of London, taking up some of the points here men. tioned. I may here relate two cases which bear upon this relation.

M. K., a married woman, aged 60, was recently under my care. There was no history of gout or rheumatism in her parents, but she had one sister, who was said to suffer from gout. She presented the lesions of rheumatic arthritis in the hands, knees, and ankles, but the hands were most affected. The muscles of both arms were distinctly wasted ; the skin of the ends of the fingers was glossy, and the soft tissues around the two last phalanges were much wasted. The right hand was affected more than the left. The tendon-reflexes were greatly exaggerated, both: at wrist and elbow, particularly on the right side. The hands showed the adduction deformity of chronicrheumatic arthritis rather than the claw of progressive muscular atrophy. The electrical reaction, of both kinds, was lessened; she had, therefore, slowly progressing in company, arthritis, wasting of muscles, wasting of tissues generally, and wasting of skin, without the reaction of degeneration. I could, in her case, detect no reflex cause. She was anæmic but not thin, and had worked hard. The case certainly pointed to a common central nervous origin of all the dystrophies. A case now under care is more interesting.

The patient, a man, following the occupation of salesman, and not the victim of overwork, has been ill for ten or twelve years. He suffered from rickets in childhood; there is no record of acute rheumatism in his own life or of any joint-affection in his ancestry. When first ill, he had occasional attacks of weakness in his limbs, accompanied by swelling in the ankles, knees, wrists and fingers, never in the shoulders or elbows. These attacks came and went, leaving him, at first, well in the intervals, but for some years he had not been possessed of proper muscular power. Two years ago he was violently shaken by a thunderstorm, since which the symptoms of which he now complains have appeared. He has, now, typical rheumatoid arthritis of the hands and feet ; the right shoulder is stiff and painful on movement, particularly in abduction ; there is grating; and a rim can be felt around the articular end of the humerus. The elbow is not involved, but the wrist is greatly distorted, almost to dislocation. There is wasting of the interossei of the hand, of the thumbmuscles, of the muscles of the forearm, and in an excessive degree of the right deltoid; the right biceps being also, but not so profoundly, wasted. There is no paresis, only such loss of motor power as would correspond to loss of muscular substance. Marked fibrillar twitchings can be seen in the arms, being more active in the right. The feet show chronic arthritis without any notable wasting of muscles. The knees are slightly affected, the hips free. There is no.loss of sensation anywhere, and no impairment of the functions of bladder or of the rectum. The deep reflexes are rather diminished, the superficial not affected. The electrical reactions of the muscles chiefly affected are impaired. The right deltoid is much less sensitive to the galvanic current than it should be, and responds only to a faradic stimulation stronger than that which should normally excite it. The biceps gives the same reactions in a lesser degree. The other muscles have normal reactions. In this case there is no history of gout, of lead-poisoning, or of causes likely to give rise to spinal trouble. These dystrophies of muscle and nerve are not accompanied by dystrophies of skin. The joint: affection was, to all appearance, preceded by a distinct accession of muscular debility.

ARticular Dystrophy brought about by Irritation of SPINAL CoRD. - If the considerations upon which I have been dwelling indicate the probability that some such influence as is excited by the spinal cord in producing muscular atrophy may produce also articular dystrophy, there are others which bring into stronger relief the influence of the spinal cord in bringing about directly affections of joints independently of muscles. I cull from my note-book a typical case of the kind. A lady, of healthy family and healthy personal antecedents, went, soon after her marriage, to an evening party. For the reception of a large number of guests, a tent was provided. Rain fell heavily all the evening, and saturated the canvas. For certain reasons, she did not dance, but sat in the tent for some hours, with her back to the wet walls, experiencing, although not actually in contact with the moisture, a sense of intense chill in the back. Within a day or two, arthritis set in in both knees. It was not intense, but presently gave rise to much swelling and deformity. The ankles, hips elbows, hands, and shoulders were in succession attacked with, the ' same trouble. : All the joints. were excessively swollen, tender, and painful; but the muscles were not noticeably affected. The joint taiffection was one, of steady progression; not one of paroxysmal exacerbaltidn followed by increased mischief, and ended. by rendering hor prac tically helpless as regarded locomotion, simply by reason of pdin: Hér muscles retained a fair bulk and strength; the reflexes were exaggerated; but it is necessary to remark that the great-sensitivemess. of the joints prevented a proper investigation. on this point. The electrical re actions were not, I am sonry to say, tested. Hor mind remained singularly clear and. well balanced; her bodily function's wer en affected; she became the mother of several children; and, in spite $i$ of locomotive difficulties, manifested an exceptional power in the diteor. tion and discipline of her household. All the effects of the long chill: received by the spinal cord seemed to fall upon the joints alone, producing, in a typical form, a progressive, rheumatic (to use the accepted term) arthritis. After reading M. Charcot's cases, one mights be tempted to wonder why: such painful affection of joints should not have been followed by atrophy of muscles. But, as a matter of obser:vation, I think, it , will generally bo found that the influences which give rise to violent :reffex reactions a are ithemsielves imastly of " tho lighter kind. Those which are superficial, call out rapid and wider spread reaction, as, for instance, an' irritating particle in the nose ? those which are deep and intense; call out the morosiconentrated reactions which end in an inflammation, or are proclaimed by severe pain. This is but a parenthesis, but it relates to a point in reflection of irritation which: is worthy of deep thought.

Óbservations of Sexiator adid others on The Nervous Pro: DUCTION OBi ARTHirits. -I might illustrate this painit ghore fúlty from my records of $i$ cases, and should 'do so, wereliatl not thet the , spinal cord . origin of certain kinds of chronic , arthritis thas been already contended for by, other observers. Senator, in his all too short paper on Arthritis Deformans in Ziemssen's Cycloporifjos, speaks thus ": "Existing observations seem to . point exclusivels to the peripheral variety of the disease, as connected with :the vaffections of the nervous: system." Remak and Benedikt were probably, the first to regard articular affections as a result of irritative states of the ispotiol marrow and sympathetic. Indeed, Remak went so far as: to call arthritis deformans by a new name, "arthritis myalitica", and "myelitico-neurotica."

The date of the publications' in which these views were advariced, is as far back as 1863 and 1864 . Senator, in his comments on them, after mentioning a case published by Kohts in 1873, in which this disease followed a fright, proceeds to say, "The usually. symmetrieal order of its invasion (the invasion of arthritis deformans), oat hardly be explained, unless we assume the existence of som central eatuses situated in the nervous system. The disease is often associgted with neuralgic and tropho-neurotic symptoms. Finally, somer' results of treatment, particularly those recorded by Remak and othersiconcern: ing the effects of electricity direated to the central nervono system, serve likewise to support this view."

That it should be regarded. by Senator as difficult to explain the symmetrical order of invasion, except upon the assumption of a eentral nervous irritation, illustrates in a forcible way the extinetion of thio beliefs of one generation by the beliefs of its successor.

Sir James Paget's Lectueres on Surgical Pathology are not imany. years old-they were published in 1853: In this most fascinating book, written by a man whom I may fairly call ; the most accomplished, as, indeed, also the most eloquent man in our professions. we find set forth, in the most convincing, way, the argument "that all symmetrical discases depend on some morbid material in the blood," and that certain blood-diseases have "seats of election." The reasoning upon which this is based is found later in the book, where, on pages 24 et seq., Sir James proceeds to develop a principte, the germ of which is in the writings of Treviranus. : Tho sentenee' of Treviranus. is, "' that each single part of the boty, in respect of its: nutrition, stands to the whole body in thesrelation of an excreted substance." According to the ideas which follotv, every part of the body has its special nutritional and excretory endowments; inasmuch as it differs from all other parts, however identical in superficial seeming, in its reaction to alterations of the blood. When there is symmetry on either side of the vertical plane, the corresponding parts agree in their reactions, while differing from all others. The second chapter-on the conditions necessary to healthy nubritioncontains a most interesting sketch of the influence of the nervous system. on nutrition; but the main ideas of causation are:independent of nervous influence, and rest on relations between the blood and the tíssues. 
The idea of some such special endowment cannot be spoken of without more than respect. It is held still, in respect of cutaneous diseases, and in respect of gout, and particularly of goutiness. I maintain that it must be still accepted as a truth, but as only a part of the truth, as regards nutrition, and I enter my protest against the short-sightedness which fails to recognise now, what Sir James Paget did, in his well balanced judgment, recognise thirty years ago, the possibility of the combined action of two dissimilar processes.

To resume now the line of thought which has been arrested by this excursion, let us, for a moment, review our position. We have considered possible causation of dystrophies of muscle by irritation of joints, of dystrophies of joints by injuries of bones, of dystrophies of joints by a sort of subjective irritation coming through channels of centripetal muscular nerves, of dystrophies of joints and muscles by irritation or disease of nervous centres.

Dicitorum Nodi-Are these all the channels by which nervous influence may affect the nutrition of joints? I think not. For more than fifteen years the probability that the form of chronic rheumatic arthritis, called by Heberden, "digitorum nodi;" by Haygarth, "nodosity of the joints ;" by Senator and others the polyarticular (I am not responsible for the hybridity of the term)-the polyarticular form of arthritis deformans, is in many cases a dystrophy, determined by nervous irritation propagated from the uterus to the spinal cord, and reflected upon the joints, has presented itself to me. Let me give briefly the notes of a case which I saw first in the year 1868 .

The subject was an unmarried lady, aged 26 . She came to me complaining of terrible dysmenorrhœa, and of what she had been taught to call rheumatic gout. She was thin, anæmic, sallow of complexion, had abundant acne on the face, and was hysterical, having given up society and all active occupation for the contemplation of her ailments. There was no small justification for this absorption. Out of every month of her life she had only one week of ease. The menstrual period lasted one week, and was attended with excessive pain in the pelvis and back. A week before its commencement the smaller joints of the extremities became swollen and excessively painful. They remained in this condition till the end of the week following the cessation of the menstrual period. There were some variations in the severity of the dysmenorrhoea, and there were corresponding variations in the intensity of the joint-affection. During the week of ease the joints showed a little deformity, but were freely movable, and free from pain or tenderness. The "rheumatic gout" was the main object of her attention, from its long persistence ; and at first I adopted the idea, already adopted by others, that the two troubles were the effect of a common cause, a rheumatic inflammation affecting joints and pelvic organs at one time. Treatment instituted upon this hypothesis failed, had long failed to give any relief, and what may be called the central position of the menstrual trouble, led me to the opinion that it was the primary mischief, giving rise, in some way that was then not very clear to me, to arthritis.

The uterine conditions were now steadily attacked. At the end of a twelvemonth's treatment, the dysmenorrhœa was subdued. As it yielded, the joint-trouble dwindled; and, with its cessation, the rheumatic paroxysms disappeared. So did the acne, the unhealthy complexion, and the general ill-health. At the present time, this lady is stout, healthy, and vigorous of mind and of body; but the joints retain some painless deformity. In the year 1869, I published an account of this case, and of others which appeared to me to indicate that uterine irritation, chiefly associated with hyperæmia of the organ, were capable of reflection upon the joints, with the result of inducing a form of rheumatic arthritis. The paper is probably little known to you, and you will pardon me if I present to you some of its matter and conciusions.

Haygarth, writing in the year 1805 , on the "Clinical History of the Nodosity of Joints," stated that he had seen thirty-three cases of that condition, all in women. He regarded the affection as peculiar to women, and as belonging to the climacteric and subsequent periods of their life. Only three out of his thirty-three cases had the "nodes" during the period of regular menstruation. Of these, two appeared to be between thirty and forty years of age ; the third had suffered twelve abortions. In all, the fingers were chiefly affected. Haygarth separated this affection as "nodosity of joints" from "rheumatic gout"a term already in use when he wrote ; and he considered it to be chiefly a disease of the middle and higher classes. Curiously enough, when I analysed my note-book, I found records of just the same number of cases-not of nodosity of joints simply, but of rheumatic arthritis, combined with decided symptoms of uterine disorder or irritation. I excluded (from the list cases in which there was evidence of uratic deposits, and cases in which no known uterine complication existed, though both classes demanded separate attention, as forming chapters of the history of arthritis.

Of the thirty-three, twenty-six belonged to the middle and upper classes, mostly to the former, the remaining seven to the poorer classes; seventeen were unmarried, thirteen were married, and three were widows.

As regards age, ten were between 20 and 30 years ; eleven were between 30 and 40 ; nine were between 40 and 50 ; and three were between 50 and 60 .

The indications of ovario-uterine complication in the several cases comprehended, marked irregularity of catamenia in two; catamenial flow simply in excess, one ; catamenial flow very scanty in one; catamenia irregular, with excess, in two ; catamenia recently disappeared in four ; catamenia recently reappeared after apparent cessation, the reappearance coinciding, with arthritic attack, in two ; dysmenorrhœa, with excess, in eight; dysmenorrhœa, with deficiency, in four ; constitutional symptoms of climacteric present in two ;fibroid of the uterus, with menorrhagia, but not dysmenorrhœa, in one ; catamenia regular, relieving pain present at other times in sacral region, in one; catamenia excessive, with leucorrhœa, in one; profuse leucorrhœa in woman married several years without pregnancy, one; woman married several years without pregnancy, one; case in which arthritis occurred on two occasions a week before parturition, these being the only pregnancies, one ; climacteric long past, arthritis began then, and has since continued, one.

In four of the above cases, ovaritis existed; and it is important to notice, first, that amenorrhœea is not noted in any case; second, that the conditions noted are mainly such as would involve hyperæmia of the internal genital organs; third, that marked dysmenorrhoea is noted in twelve, or more than a third of the total number.

The seat of arthritis was various. It affected the hands alone in thirteen cases ; the hands, wrists, and elbows in three ; the upper extremities in one; the right hand only in one; the right hand and wrist in one; the hands and feet in one ; the hands, feet, and knees in one; the knees and ankles in one; both extremities in six; both extremities on one side in one; the ankle and tendo Achillis in one. From this, it appeared that the hands were more often affected than any other parts, the metacarpo-phalangeal joints being of all joints the most obnoxious to this form of arthritis. The hands, besides being alone attacked in thirteen cases, shared the affection with other joints, and principally with other joints of the upper extremity, the wrists excepted, in all the rest of the cases, except two. In three of the cases, where the affection was limited to one side of the body, or having begun, continued excessive, on one side, there were ovarian pain and tenderness on the same side, and a distinct frequency of neuralgia on the same side.

A further inspection of the cases brought out most interesting relations. Not only did the arthritis coincide with ovario-uterine affection, but, in a considerable proportion of cases, paroxysms of arthritis coincided with menstrual periods. This sort of parallel march was noted in fourteen cases, in one of which arthritis preceded menstruation as its regular herald; in seven, arthritis regularly accompanied; in two, it followed; in two, it both accompanied and followed; and in two, arthritis occurring in the intervals was relieved by menstruation.

Now, if these had been so many cases of dysmenorrhœe, the occurrence might perhaps have been accepted as an argument for believing the dysmenorrhœe token to be a part of a general rheumatic process. But, though the conjunction was reported in seven, it was conspicuously absent in as many cases; and these are precisely the instances which do most to prove that the arthritis is a product of the uterine hyperæmia. With this simple question we will deal for a moment, leaving the modus operandi to be discussed later on.

Among the seven cases referred to as not accompanied by dysmenor. rhœa was that of a lady then 52 years of age. She had had a large family -in all twelve-and it was then as much as five years since she first began to suffer from arthritis. Before the arthritis troubled her, she had begun to experience excessive menstrual loss. She consulted, for this, a distinguished gynæcologist, who found the uterus enormously engorged, but otherwise free from disease. The engorgement was lessened by treatment, but not by any means cured, and the menorrhagia went on. The arthritis first came in the form of sharp inflammation and swelling of the knuckles of both hands, rendering them completely useless. It began usually on the second or third day of the menstrual flow, and continued as long after its cessation. The periods becoming more frequent and lasting longer as time went on, she became reduced to a very pitiable state. She was anæmic, exceedingly feeble, was crippled in hands, wrists, and knees, and lost her rest by reason of what she called "fidgets," uneasy but indefinable sensations in her limbs and abdomen, unaccompanied by pain or spasm. 
Change of air and of scene, baths, tonics, alteratives, were all used, in addition to local remedies, but no relief was obtained till, as she reached the age of 50 years, the periods began to be less frequent.

At length, intervals of two or three months occurred, and allowed her to gain strength, when she lost her arthritis and her fidgets, and appeared perfectly healthy. Of late, the periods had been still further apart; but still, whenever the catamenia appeared, she was once more crippled.

The association of the arthritis with this painless menorrhagia began clearly at a time when the patient was weakened and drained of blood. The fidgets illustrated the irritability of the spinal cord, related with imperfect nutrition, and the arthritis came out as a resultant of two conditions : uterine irritation and spinal sensitiveness.

I may add that I have seen this lady within the last few weeks, not as a patient ; that the catamenia have entirely ceased for three years that she has had no joint-trouble since, excepting on one occasion, when it occurred in conjunction with severe intestinal catarrh; and that she is now ruddy, well nourished, active, and cheerful.

A lady, aged 51, the mother of six children, came to me in 1882 with a gouty-looking inflammation in the elbows, wrists, hands, and knees. This had occurred a day after the return of the catamenia, previously absent for twelve months. She had no signs of gout in the shape of deposits, and her own expression was, that she felt the attack to be really "in the nerves." The period was short, and the arthritis disappeared. But the catamenia having since returned with unusual freedom and duration on two occasions, she had each time had the arthritis severely enough to cripple her. The arthritis came on at the end of the periods, the last of which was accompanied by abdominal pain, a circumstance hitherto unknown to her. I am now able to report of this case that the catamenia have ceased, and that the joint-affection is forgotten.

I might multiply my citation to a large extent, for the relation lis illustrated constantly now that it has once been recognised.

Hypothesis of Reflex Causation of ARthritis by Uterine IrRiTATION. - The argument which was founded upon these cases and others not now quoted, had the following general bearing: that, seeing this frequent coexistence of a certain kind of inflammation of the joints with uterine hyperæmia, seeing also that the joint-inflammation increased in intensity in a very marked proportion to increase of the uterine hyperæmia, and that, also, when the signs of uterine hyperæmia ceased the joint-affection passed away, there was reason to regard the one as caused by the other. The joint-affection had in itself no necessary property of permanency. The uterine affection had of a necessity a beginning and an end, and the joint-affection was noticed only during its existence. If, from such considerations, it was fair to infer that the dystrophy of joints was, in some way, brought about by an abnormal condition of the uterus, the intermediate conditions linking the two had next to be sought for. That there was some intimate relation between inflammations of the joints and uterine conditions more or less approaching inflammation, had not escaped the acute observation of the late Dr. Todd. In his Croonian lectures for the year 1843, he had written : "It is remarkable how frequently this affection" (the symmetrical nodosities of the hands, called by him "chronic rheumatism of joints") "occurs in women, and how rarely in men; and there are many facts which indicate that, in the former, it may have an uterine origin, either connected with the puerperal state, or from a defective or difficult catamenial action." $\mathrm{He}$ was in clined to believe that "the unhealthy secretions of the uterus afford material for the production of rheumatic matter." In these lectures he quotes Sir Henry Holland, Sir Charles Locock, and Dr. Rigby, as authorities in favour of the opinion that there is some connection between the sexual functions and the causes and course of gout and rheumatism.

Another good observer, Dr. Fuller, had spoken decidedly as to the fact, that "rheumatic gout attacks women rather than men." "I fixes," he had said, "upon the girl just arriving at puberty, whose menstrual functions are ill performed, and it occurs frequently at the cessation of menstruation, or during the debility which follows on a miscarriage, or a difficult or protracted labour, more generally when complicated by flooding." These authors found the explanation of the relation which they so closely acknowledged in the suggestion of a virus, generated in the uterus, absorbed by the blood, and attacking, in virtue of some elective affinity, the joints.

If we consider the many cases in which acute rheumatism occurs immediately after parturition, in the early weeks of lactation, we may acknowledge that the sequence of morbid phenomena lends much support to a hypothesis of this kind. We must acknowledge that the condition of the uterus after parturition provides a large quantity of septic, inflammatory, and quasi-inflammatory matters; that its vascu- lar arrangements are such as to offer a ready access of these matters to the circulation; and that where these matters are undoubtedly septic, and where they find access to the circulation, in the septicæmia or pyæmia which follows, the joints are among the organs most frequently invaded by the poison so introduced into the system. But in this, as in other forms, the joints are by no means the only subjects of attack. The viscera are, at least with equal frequency, the seat of this secondary affection. In the acute rheumatism associated with the conditions just mentioned, the serous membranes, and the lungs, and the veins, are frequent sufferers from the inflammation which primarily attacks the joints ; but they are more rarely affected without intercurrence of a jointaffection, although, in pyæmia, it is certainly not rare to find the joints spared, while the viscera show fatal lesions. In the nodosity of the joints, which I have presented to you as simultaneous with, and in its variations parallel with, uterine hyperæmia, there is, so far as I have been able to make out, no corresponding visceral inflammation of either acute or chronic kind. If a blood-condition, having some quality of attenuated septicity, were the agent, the viscera ought in fairness to share in the injury. We may remember that the presence of lactic acid in the blood has been adduced in explanation of the phenomena of acute rheumatism, and, perhaps, more particularly of acute rheumatism breaking out during lactation. This very neat hypothesis has been supported by names of great authority, and rests on the observations that the administration of lactic acid to men and animals is followed by joint-affection, and that lactic acid has been found in the blood during acute rheumatism. The whole theory resting on these somewhat slender bases cannot, I think, apply in any way to the joint-affections considered in the early part of this address, where the only obvious lines of causation were nervous.

There are not a few considerations which induce me to oppose to this humoral and chemical view, the view of nerve-agency. Putting aside those peculiarities of personal constitution which render certain persons prone, under many circumstances involving febrility, $\mid$ to develop joint-affection, particularly acute rheumatism, I would represent that at least a very large majority of the women having nodosity of the joints, or arthritis deformans, present in the first place a marked hyperæmia of the os and cervix uteri. That these organs have the power, through centripetal nervous influence, of producing enormous excitement in the spinal cord is the next point which may be taken. Sometimes the excitement may show itself by pains in limbs, sometimes by flushings of skin, sometimes by swellings of the breasts. Sometimes, as it appears to me, the effects of excitement may be reflected along the same paths which in primary affection of the spinal cord have led to affections of joints. Moreover, the state of the patients under consideration is generally one of debility, often one of anæmia. It is a matter of daily experience that in such conditions the reflex excitability of the spinal cord is increased; it explodes, so to speak, on the application of impulses which, in its proper nutrition, it would transmit. And so both the local and the general state would conduce to the reflection.

Gonorrheal Rheumatism. - There is yet another form of arthritis in which it appears to me possible to call in the agency of the nervous system. I speak of gonorrhceal rheumatism, so called. In this disease, as we know, an arthritis having no differences in its local morbid anatomy from the lesions already discussed comes on during an attack of gonorrhoea, often in company with ophthalmia or sclerotitis. When the gonorrhœa ceases the joint usually gets well. The arthritis is easily induced afresh by new attacks of gonorrhœa. There are, however, some variations in progress and relation. The arthritis sometimes coincides with, sometimes alternates with, the gonorrhœeal flow. It sometimes persists, particularly in the knees and ankles, producing chronic changes leading to "white swelling," or a kind of ankylosis. The affection is only seen in males. Ricord gave it the name of "blennorrhagic arthritis," which is to my mind a far better term than gonorrhœal rheumatism. As regards its diagnosis, he asserted that the only real difference between this form of arthritis and all the others is to be found in the cause which gives rise to it. Brodie, Elliotson, Fuller, and others, have cited cases in which a simple, that is to say not gonorrhœal, urethritis has had associated with it the same three disorders, arthritis, conjunctivitis, sclerotitis. It is hard, of course, to prove a negative, but we have the evidence of the abovenamed excellent observers, that they at least accepted, in these cases, the absence of gonorrhœal taint as a fact.

I have seen lately a gentleman suffering from a third attack of the kind. He is gouty, lives temperately, but works very hard. On three occasions he has had severe purulent urethritis, which he asserts to be absolutely unconnected with any possible source of gonorrhœal 
kind. This is followed by sharp arthritis, and sometimes by gouty inflammation of the toe, lasting until the discharge, which is very obstinate in resisting treatment, is checked. The patient is a man of the world, and I believe his statement. His own belief is that all the phenomeria are gouty.

Blenmorrhagic arthritis has naturally been attributed to some specific infection of the system from the urethra, and consequent infection of the joints; but if the concurrence of a similar arthritis, with nonspecific urethritis, be admitted, the theory of a specific poisoning is considerably weakened. If it be acknowledged, again, that so called gonorrhoul rheumatisn is a disease only seen in men, the difficulty of accepting the specific idea is increased.

Women certainly do sulfer from gonorrhœe, and I can conceivo no reason why, if they have it, they should not be poisoned by it in the same way as men arc. The more I think over the matter, the more do I see to suggest a parallel between the nodosity of the joints in women, so often associated with irritation of the uterine surfaces, and the blennorrhagic arthritis associated in men with inflammation of the urethral surface, particularly if the prostatic part of the urethra be affected. That excitements of the prostatic part of the urethra, particularly of the floor, have enormous influence upon the spinal cord, is shown by the phenomena of sexual intercourse. The widespread indescribable sensations which attend emission, and the exhaustion which follows, testify to this. Most of us have, no doubt, been consulted by men, chaste in act, who are tormented by sexual excitement. They tell one stories of long-continued local excitement, followed by intense muscular weariness, or by some severe aching pain in the back and legs. In some, I have had complaint of swelling and stiffness in the legs, and of pains in the joints, particularly in the knees. Conditions of this kind indicate an effect upon the spinal cord which is very nearly reacting in trophic influence upon the limbs. I may relate a cass in which it sems to me that an actual trophic influence was exerted.

A gentleman, aged 30, who had lost his wife about two years before, came to me with painful affection of the knees. Both knee. joints were greatly distended with fluid and were tender, but not much heated. The condition reminded one of the " arthropathie des ataxiques ;" but no other sign of tabes dorsalis could be detected then or since. I tried various remedies without success, and he went to many doctors and many baths, without obtaining a cure; though at last with some relief. Then he married again. Not long after, he came to tell me that he was quite well. He also told me, upon my asking him as to his lachelor life, that he had been almost constantly harassed by the thorn in the flesh, but that he had been absolutely chaste, and he himself was of opinion that marriage had been the means of cure. I hear of late (some seven years after the second marriage) that his joints are getting bad again, and at the same time, that his wife suffers from a uterine affection almost altogother preventing colialitation. Upon such grounds as the foregoing considerations afford, I suggest it is possible that irritation of nerve cells in the spinal cord, carried to them through channels of urethral nerves, may set up an excitement in those cclls giving rise to irritative processes in the joints supplied by them. M. Charcot's cases already referred to indicatc rather a process of inhibition than anything else ; of torpor, as he says, of the nerve-cells under centripetal stimulation coming from joints.

Urinany Pararlegia. - In relation with the idea that irritation is set up in joints by irritation reflected from viscera, I am tempted to point to the so-called reflex or urinary paraplegia as illustrating, possibly, a torpor set up in the nerve-cells of the cord, ing from viscera. The name reflex paraplegia, given by Brown. Séquard, has been of late replaced by a safer term-urinary paraplegia. But, whicherer name we use, we recognise that an urethral irritation, most commonly dependent on a stricture, is so joined with paralysis or paresis of the lower limbs as to make it probable that the stricture is a cause of which the paraplegia is an effect. The objection-a just one-to the application of the term "reflex" lies in the tact that the paralysis can sometimes be traced to myelitis, in the lower part of the cord, sometimes to neuritis. But, in a certain number of cases, no lesion of corl or nerves has been detected, and to such cases, where the paraplegia and the urethral irritation were the only coexistences, the term reflex might be applied. I do not speak here of other reflex paraplegias. I merely wish to indicate the possibility of some such nerve-relations existing between the urethral surface of joints, carried on by the mediation of the nerves and cord, and to compare them with such relation as we have been treating of as probably existing between the joints and muscles through the cord.
Enough, you will say, of the joints and their neurotic dystrophies. Too little, I reply; for time forbids me to discuss the neurotic dystro. phies of gout.

NeUROTIC DYstrophizs of Seckirtion.-I am compelled to go on to another subject, and to direct your attention to some neurotic dystrophies of secretion. Some of the most striking of these are certainly hard to be understood. So far as I am aware, it is not known why the breath of a man, who has undergone great and concentrated mental anxiety, should suddenly become fetid ; or why the milk of a woman, whose emotions of fear or anger have been violently excited, should prove poisonous to the infant at her breast?

Glycosuria in Relation to Nerve-INFLUence.-Suggestions, illustrating the mode in which such dystrophies come about, may not unreasonably be afforded from a consideration of what is known with regard to the production of glycosuria. Not long ago, I reviewed my notes of cases of glycosuria, unattended by diuresis ; such cases occurring almost entirely in persons over fifty years of age. Since the time of Bernard's great discovery, a long series of experimental physiologists has been engaged in working out the influence of the higher centres, and of the sympathetic, in producing glycosuria. Pathological investigation has brought many good observers to the belief that true diabetes mellitus is caused by disease of the central nervous system. It must be admitted that this point is still far from settled. In the non-diabotic glycosuria of comparatively old people, we may see a dystrophy coexistent with disorders of various kindsdisorders, for the most part, more pressing than itself-in such relation that we may be justified in reducing it to the rank of a symptom. If it can be regarded as a symptom, we may have a reasonable probability of arriving at a notion of its causation by an examination of its coincidences or its coexistences. As regards the onset of true diabetes, the frequent antecedence of great emotional disturbance of the central nervous system has been recognised by general consent. Dr. Dickenson has collected a large number of illustrations of this connection, in his work on Diseascs of the Kidneys. In the cases which I have anslysed, one-third of the whole number told a story of cxcessive or prolonged mental work or anxiety preceding the rocognition of glycosuria.

In one, after much emotional excitement, insanity was at last fully declared. In one, after a long course of strenuous mental labour, scarcely intermitted during the nights of many years, hemiplegia oclead on to another group, in which glycosuria appeared as a symptom of actual disease of the nervous system.

In two cases, there was marked tabes dorsalis, and in a third, locomotor ataxy was present, with additional signs indicating affection of the whole breadth of the spinal cord. Decided hypochondriasis was noted in two casos. One of the patients was haunted by the dread of syphilitic disease, but manifested no signs thereof whatever. In a third group, marked signs of nervous disorder accompanied the glycosuria, to wit, tinnitus, vertigo, sleeplessness in an extreme degree, conlimbs, sciatica, shingles, prurigo, and marked loss of muscular energy. In three cases, the patients were the subjects of a very typical form of angina pectoris. I may add that I have since seen another illustrution of this coexistence. To sum up, there was scarcely a case in which glycosuria was not associated either with evident discase of the central nervous system, or with symptoms indicating great perturbation of the centres of the nerves. A second stage of observation brings out a new set of relations. In more than a third of the cases, true gout was distinctly present. In a much smaller number, chronic rheumatoid arthritis. A third of the patients admitted habitual overindulgence in alcoholic stimulants.

The multiform relations of glycosuria here exhibited would lead to the inference that the ultimate causes are of many kinds. We may recognise the excess of sugar in the blood giving rise to glycosuria as having at least a sixfold origin. Putting aside causes consisting in disproportion between the amount of saccharine matter introduced into the system and the capacity of the liver for transforming it, or in varying stability of glycogen, or in diminished use of sugar by the system, we come to the discussion of the increased decomposition of glycogen determined by increased afflux of diastatic ferment. To put this in other words, we come to the consideration of dilatation of the hepatic artcry and its branches allowing of an increased inflow of ferment-containing blood. By such kind of intermediste influence, it is probable that irritations and irritability of the nervous system can be conceived to set up the glycosuria. Irritation of hepatic nerves in alcoholism and diseases of the liver, irritation of the pneumogastric in the stomach or in the heart, irritations of the pneumogastric arising in other peripheric stimulation, can conceivably be reflected in 
a pathological way as they are known to be in a physiological way; and, in the most typical of the cases which I have analysed, I have had presented to me as causative of glycosuria at the same time signs of deep gastric or hepatic disorder, and signs of general nerrous irritability.

Gout AND Guycosuria.-Gout and glycosuria have been seen in tolerably frequent association in many cases. Dr. Gairdner pointed this out many years ago. Dr. Lauder Brunton has used the term gouty glycosuria. I am tempted, after much thinking, to ask whether the expression "gout of the liver" may not be appropriate; to ask whether we may not entertain the idea that, in many people, there may exist a more or less constant arterial hyperzemia of the liver, comparable to the acute hyperamia of joints undoubtedly an essential factor of acute gout.

ACUTE INFlammation of Diabetes and Nerve-infidence. In true diabetes, the occurrence of sudden and very acute visceral inflammations is common. It is generally found that, while such complications last, the urinary sugar dwindles, or even disappears. An explanation of this occurrence has been found by some writers in the hypothesis of an increased combustion of sugar as a part of the pyrexial state. But, seeing that such inflammations involve the diversion of a large quantity of blood to the organ affected, I venture to suggest that in such diversion, rather than in a purely hypothetical combustion, may be found the true explanation. Physiological experiment has shown that, when sections of the sympathetic, leading to vaso-motor dilatation of the hepatic vessels alone, has been made, glycosuria has been produced; that, when the section has been made at a point producing, in addition to dilatation of the arteries of the liver, dilatation of the vessels of the intestines, glycosuria has not followed. The inference drawn is to the effect that so much arterial relaxation was produced in the supply of organs neighbouring to the liver as to stand in the way of an effective increase in its arterial circulation. I had an opportunity quite recently of testing the probability of this hypothesis. The temperature of a diabetic patient rose suddenly to $104^{\circ}$ Fahr. The most careful examination brought out no signs of visceral inflammation during two days; and in the same period the amount of sugar in the urine stood at the figure registered for several weeks before. On the third day, the temperature remaining at the same height, the signs of pneumonia became apparent, and at the same time the urinary sugar diminished very considerably. In my gouty cases, a similar train of phenomena has been soveral times noted -the sugar diminishing in a very marked degree at the time of the development of acute joint-inflammation, and returning immediately on its subsidence.

In trying to understand the sudden acquirement of a poisonous quality by the milk of an agitated woman, one had found a difficulty of this kind-could mere quantitative variations in the afflux of blood affect the quality of the secretion? Can it be possible that, in the production of the lacteal secretion, may be concerned not merely increased afflux of the materials of the secretion, but also varying afflux of ferments determining its quality, and capable, by reason of either great deficiency or great excess, of seriously perverting its quality? Here is an admitted neurotic dystrophy, the mechanism of which is well worth careful investigation ; and from the consideration of glyco. suria we may be enabled to glean at least suggestions as to what the mechanism may be.

The Nervous Relations of MrxadeMa.-Let me, leaving many points which are tempting, go on to say a few words about another class of neurotic dystrophies, namely, about those occurring in myxadema, occurring therein to such an extent as to constitute the predominant symptomatology of that disease. We may recognise in myxcedema three principal lines of nervous abnormity.

First, intellectual; consisting in slowness of thought, in slowness of volition, in loss of memory, in irritability of temper, in unwarranted suspicions, in delusions, in actual insanity, or in torpor growing to

Second, in sensation. General sensation undergoes a change, to which the term bradæsthesia is applicable; the recognition of impressions made on the surface is distinctly retarded; the sensibility to sensa. tions of heat or cold is blunted; and there are often noted, abnormal subjective sensations, particularly affecting the sense of taste and smell.

Thirdly, the motor powers are disturbed in a singular way; all motion is slow ; co-ordination is imperfectly adjusted ; certain groups of muscles become unduly relaxed, and are stimulated to action only by strong exercise of volition. Reflex actions are produced with considerable delay. In some cases, evidences of more localised nervous impairment oc. ?ur, in particular the signs of bulbar paralysis. It may be argmed, on the one hand, that this remarkable assemblage of nervous dis- orders points to the nervous system as the seat of the original cause of the discase; on the other, that the obvious changes in the state of the connective tissues throughout the body may affect the nervous centres and put their morbid reactions into the category of secondary conditions. It is a question, that is to say, whether Inyxcedema be a neurotic dystrophy, or whether the disorders of the nervous system are produced by an alteration of connective tissues, having an origin, like that for instance of lardaceous disease, independent of nervous inflence, -chemical, degenerative, inflammatory, or other. The remarkable atrophy of the thyroid body observed in this disease, and the relation which is by many regarded as existing between that body and the sympathetic system, have brought some thinkers to the belief that the disease arises primarily neither in affections of the cerebro-spinal system, nor in altered nutrition of the connective tissues. Those who are induced to take this view have found the explanation in primary alteration of the sympathetic system; in alteration of the sympathetic system somehow determined by the atrophy of the thyroid, or in alteration of the sympathetic system determinal iy chronic apyretic inflammations within the chest, particularly in the pleara. What can be said is that in this disease there can be recomiced an enormous dystrophy of connective tissues; that the dystropiny has certain aspects of degeneration; that, again, in the increase of nuclei, it has some aspect of over activity; and that, so far, it may suggest the occurrence of a low form of inflammatory process inducing degeneration of the tissues involved : or that, on the other hand, a degeneration has induced a very elementary inflammatory process in the tissues. The atrophy of the thyroid may conceivably be bronght about hy the changes of the connective tissue which we can see in the other parts of the body, leading, by the aggressive hypertrophy of that tissue, to pressure on, and atrophic changes in, immeshed glandular tissues. But here we must hold our hand, for there is another side to the question. Kocher and others in Switzerland have of late ycars been cutting out enlarged thyroid glands, and have recorded the secquence upon this operation of slow development of a condition which, as produced and described by them, corresponds exactly with myxcedcma as observed in England. The interest of the observation is intensified by the circumstance that these operators, in making this recorl, were not aware of the observations on myxœedema made in this country.

The true function of the thyroid body being undetermined, one may hope that the concurrent observations may converge in such a way as to throw light on a very obscure lis of physiology ; but it is hard to resist the conclusion that, through some nervous channels, the thyroid body influences the nutrition of the connective tissues generally; and may, perhaps, also influence the nutrition of the cerebro-spinal centres.

To put the matter in another way, the great tendency of existing observations is to class myxoedema among neurotic dystrophies.

I should have liked, if I could have brought them within the com. pass of this address, to have said something about the neurotic dys. trophies of the skin, but must, however, reluctantly leave them un. touched.

Many here will think that I should have said something about the dystrophies incited by surgical injuries of nerves. These last, indeed, offer possibilities of more exact treatment than any of the dystrophies which have engaged our attention. The observations of Weir Mitchell, Brown-Séquard, Hutchinson, and others, have been, in some unconscious fashion, directing my thoughts to the choice of the subject of to-day's address. Let me acknowledge this fully; and let me ask you to understand that I have to-day merely been putting before you the result of obscrvation and thought, set going ly the reading of the works of predecessors and contemporaries. Each succeeding generation in science gathers the lines of older and recent vision into some focus, more or less of its own choosing. The wislom of the choice is to be judged by the generations still succeeding. What shall be the outcomo here?

Royal GifT. - Her Majesty the Queen has presented a copy of More Leaves from the Journal of Our Life in the Highlends, with autograph inscription, etc., to the Royal Hospital for Diseases of the Chest, City Road, London, of which Her Majesty is the Patron.

Medical Magistrate.-Dr. Lewis Wayne Morgan, of Pontyprada, has been appointed a justice of the peace for the county of Glamorgan.

Foreign Graduates' Association. - Dr. W. C. Daniel, of Epsom, has been elected President for the ensuing year, vice Dr. H. J. Hard-
wicke, of Sheffield, who becomes a Vice-President. I)r. K. N. Macdonald, of Cupar, a former President, has been electel a Vice-President ; and Dr. J. J. Bailey, of Marple, Honorary Secretary. The Council consists of twelve London and provincial foreign graduates. 